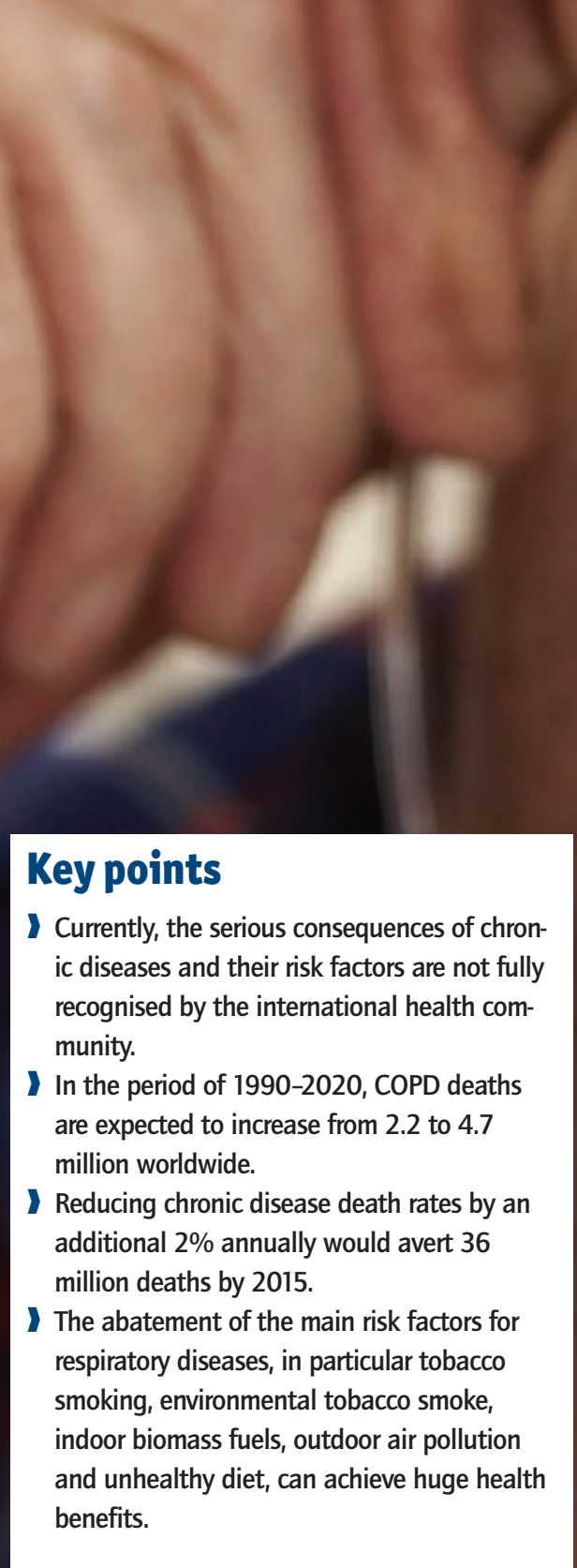




\section{The global burden of chronic respiratory diseases}

\section{Educational aims}

1 To define the burden of chronic respiratory diseases all over the world.

1 To underline the importance of chronic diseases recognition by the international health community.

1 To provide details about the burden of chronic obstructive pulmonary disease (COPD): the predicted third cause of death by 2020.

\section{Summary}

Currently, the serious consequences of chronic diseases and their risk factors are not fully recognised by the international health community. Moreover, chronic diseases are not only a problem of the ageing population in developed countries. In fact, it has been estimated that $80 \%$ of mortality for chronic diseases occurred in low-income and middleincome countries in 2005. Thus, the World Health Organization (WHO) Dept of Chronic Diseases and Health Promotion has suggested a new Millennium Development Goal for the next few years: to reduce chronic disease death rates by an additional $2 \%$ annually, in order to avert 36 million deaths by 2015.

By the year 2015, all 191 United Nations

Member States have pledged to meet eight Millennium Development Goals (table 1). The health goals are concerned with a reduction in child mortality, an improvement in maternal health, and the combat of HIV/AIDS, malaria and other diseases. Thus, the serious consequences of chronic diseases and their risk factors are not being considered by the international health community, at least in terms of financial commitments by health and development agencies (box 1).

According to the Dept of Chronic Diseases and Health Promotion of the $\mathrm{WHO}$, the main chronic diseases include cardiovascular diseases (CVDs) (30\% of projected total worldwide deaths in 2005), cancer (13\%), chronic

\section{Table 1 The Millennium Development Goals \\ 1. Eradicate extreme poverty and hunger \\ 2. Achieve universal primary education \\ 3. Promote gender equality and empower women \\ 4. Reduce child mortality \\ 5. Improve maternal health \\ 6. Combat HIV/AIDS, malaria and other diseases \\ 7. Ensure environmental sustainability \\ 8. Develop a global partnership for development}

respiratory diseases $(7 \%)$, and diabetes (2\%) (figure 1). Chronic diseases are often defined as problems of ageing communities, mainly caused by tobacco use, unhealthy diets and physical inactivity $[1,2]$. According to $\mathrm{WHO}$, in Europe, $86 \%$ of deaths are caused by chronic

\section{S. Maio $^{1}$ \\ S. Baldacci ${ }^{1}$ \\ L. Carrozzi ${ }^{1}$ \\ F. Pistelli ${ }^{1}$ \\ G. Viegi1,2}

1 Pulmonary Environmental Epidemiology Unit, Institute of Clinical Physiology, National Research Council (CNR), Pisa, Italy.

2005-2006 President, European Respiratory Society (ERS).

\section{Correspondence:}

G. Viegi

Pulmonary Environment

Epidemiology Unit

Institute of Clinical

Physiology

National Research Council

(CNR)

Via Trieste, 41

56126 Pisa

Italy

E-mail:viegig@ifc.cnr.it

Fax:39050503596 


\section{Box 1. The cost of inaction is clear and unacceptable}

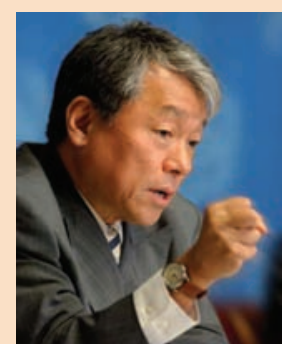

Dr Jong-Wook Lee', the Director General of the WHO, in his message for the World Global Report of WHO (2005) said: "The lives of far too many people in the world are being blighted and cut short by chronic diseases such as heart diseases, stroke, cancer, chronic respiratory diseases and diabetes" [3].

Dr Jong-Wook Lee died on the morning of May 22, 2006, following a sudden illness. The authors of this review, as well as all members and staff of the ERS, extend their most sincere condolences to Dr Lee's family. Dr Lee, who worked for 23 years at the WHO, led his organisation to continue its mission to help people attain the highest possible level of health.

diseases (figure 1) [3]. However, chronic diseases are also a large problem in low-income countries (especially among those who do not have the resources to improve their quality of life). Recent evidence suggests that deaths from cardiopulmonary diseases and lung cancer occur at earlier ages in low-income and middle-income countries where prevention is not a priority. It has been estimated that 35 million people died in 2005 from heart diseases, stroke, cancer, respiratory diseases and other chronic diseases. Only 20\% of these deaths were in high-income countries, while $80 \%$ were in low- and middle-income countries (especially among adults aged 30-69 years). The impact on males and females was similar. Therefore, a new goal proposed by the WHO is to reduce deaths from chronic diseases by an additional $2 \%$ per year, in order to avert 36 million deaths by 2015. Moreover, this goal would permit a gain of $\sim 500$ million years of life over the decade from 2006 to 2015 [2].

\section{Projection of mortality rates for chronic diseases}

Figure 1
Estimated proportion of chronic deaths in Europe, China, India and all over the world (2005). Figure adapted from [3].
STRONG et al. [2] presented the mortality and burden of disease projections for chronic diseases using the WHO 2002 mortality estimates as a

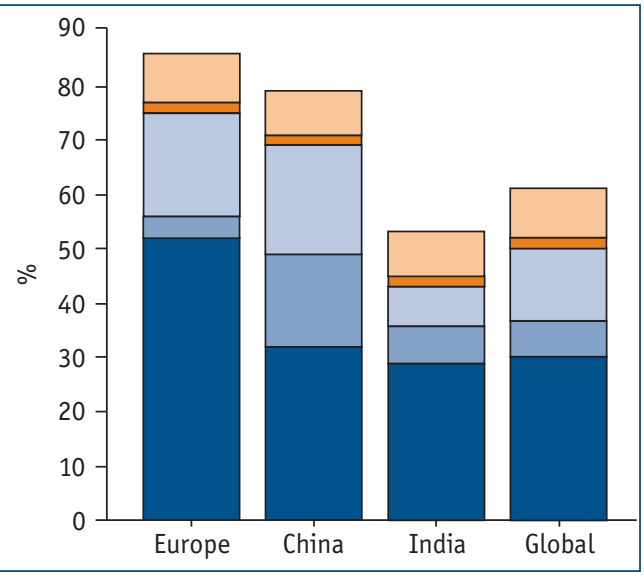

baseline [3]. Globally, $\sim 58$ million people died in 2005. This value is projected to rise to 64 million in 2015. The distribution of these deaths across three major cause groups showed the following: mortality of $30 \%$ for communicable, maternal, perinatal conditions and nutritional deficiencies; mortality of $61 \%$ for chronic, non-communicable diseases; and mortality of $9 \%$ for injuries. When the results are studied in detail, respiratory diseases are the third leading single cause of deaths worldwide (7\%) (figure 1). The projected number of chronic disease deaths will rise from 15 million in 2005 to 17 million in 2015. Conversely, the age-specific death rates for those aged $<70$ years will remain the same or decline between 2005 and 2015. The burden of diseases (disability-adjusted life-years lost; DALYs) will rise from 626 million in 2005 to 693 million in 2015 , in people aged $<70$ years. The global chronic disease goal (reducing deaths from chronic disease by an additional $2 \%$ annually) would determine an estimated 36 million fewer chronic disease deaths, of which 28 million would be in low-income and middle-income countries, in the same time interval. For people under the age of 70 years, the global goal would result in 3 million fewer deaths in 2015. These figures support the overall goal of chronic disease prevention and control, which is to delay mortality from these diseases to older age groups and to promote healthy ageing of global populations [2].

\section{Chronic diseases in South-East Asia and Western Pacific regions}

As mentioned above, $80 \%$ of deaths from chronic diseases occurred in low-income and middleincome countries in 2005. REDDY et al. [5] have previously presented the estimated proportions of total deaths and DALYs in India. They 
estimated that in 2005, $53 \%$ of deaths would be caused by chronic diseases in India when compared with $61 \%$ of deaths all over the world (figure 1). Moreover, chronic diseases will cause $44 \%$ of DALYs. Previously, the Global Burden of Disease Study projected that the number of deaths attributable to chronic diseases would rise from 3.78 million in 1990 (40.4\% of all deaths) to 7.63 million in 2020 (66.7\% of all deaths) [4], and that many of these deaths would occur at relatively early ages. In conclusion, REDDY et al. [5] underlined the need to increase resource allocation, to coordinate multilevel policy interventions and to enhance the engagement of the health system in activities related to chronic disease prevention and control.

WANG et al. [6] have previously presented the estimated proportions of total deaths and DALYs in China (figure 1). Compared to India, China showed higher estimates for chronic diseases mortality (80\%) and DALYs (70\%). Moreover, China has the highest rate of deaths from chronic diseases in middle-aged people worldwide. It was reported that in China, as in many other parts of the world, the government has focused on communicable diseases. However, fortunately, the prevention of chronic diseases is now receiving a national response commensurate with the burden [6].

$\mathrm{HE}$ et al. [7], who studied the change of the disease burden in China caused by the rapid economic development of the country, suggested a control of hypertension, smoking cessation, increasing physical activity and improvement of nutrition would help in reducing the burden of premature deaths among adults.

\section{The global burden of COPD}

According to the WHO, COPD (12th cause of disability and the 6th cause of mortality in 1990) will be the 5 th cause of disability and the 3rd cause of mortality by 2020 worldwide [8]. The main cofactors responsible for this remarkable increase are tobacco usage and ageing, especially in developing countries.

With regards to the global burden of COPD, CHAPMAN et al. [9] have reported that the prevalence of COPD in the general population is estimated to increase with age, reaching $~ 10 \%$ amongst those aged $>40$ years. LOPEZ et al. [10] reported that $\sim 2.7$ million deaths from COPD occurred in 2000, half of them in the Western
Pacific region, with the majority of these occurring in China. About 400,000 deaths occur each year from COPD in industrialised countries. Another 650,000 COPD deaths were estimated to have occurred in the South-East Asia region, largely in India (figure 2). All over the world, $1.9 \%$ of DALYs were attributable to COPD in 2000 (figure 3). These results confirm that chronic diseases are a leading cause of mortality in low-income and middle-income countries, such as China and India [10].

In the PLATINO study, Menezes et al. [11] evaluated the prevalence of COPD in subjects aged $>40$ years living in five major Latin American cities: São Paulo (Brazil), Santiago (Chile), Mexico City (Mexico), Montevideo (Uruguay) and Caracas (Venezuela). The results showed that adjusted prevalence rates for COPD ranged from approximately $12 \%$ in Mexico City to around $20 \%$ in Montevideo.

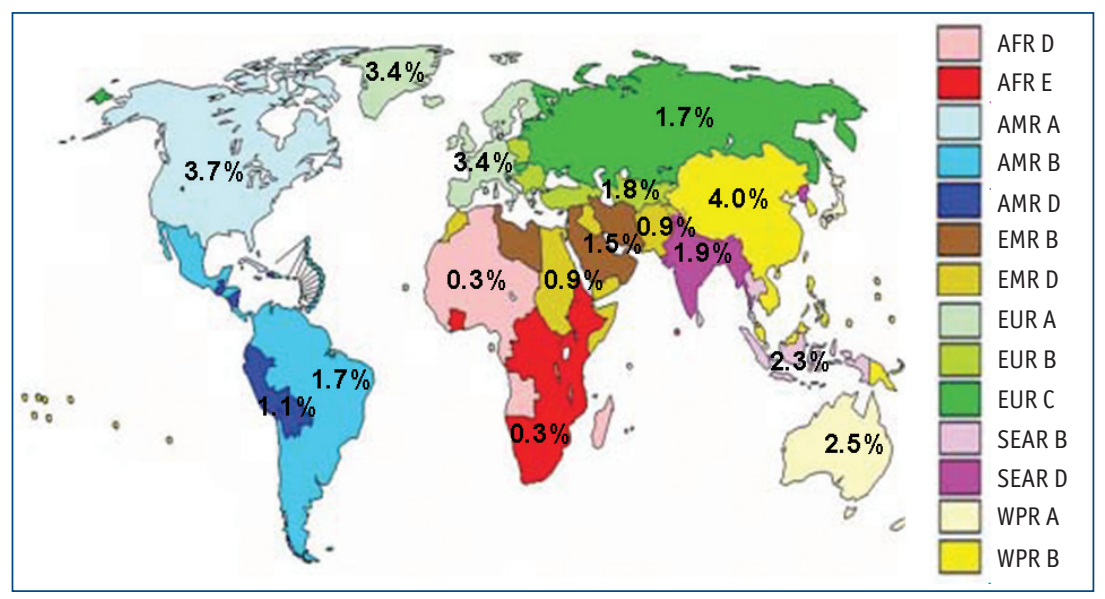

Figure 2

Estimated COPD deaths by WHO regions, 2002. Figure modified from [10].

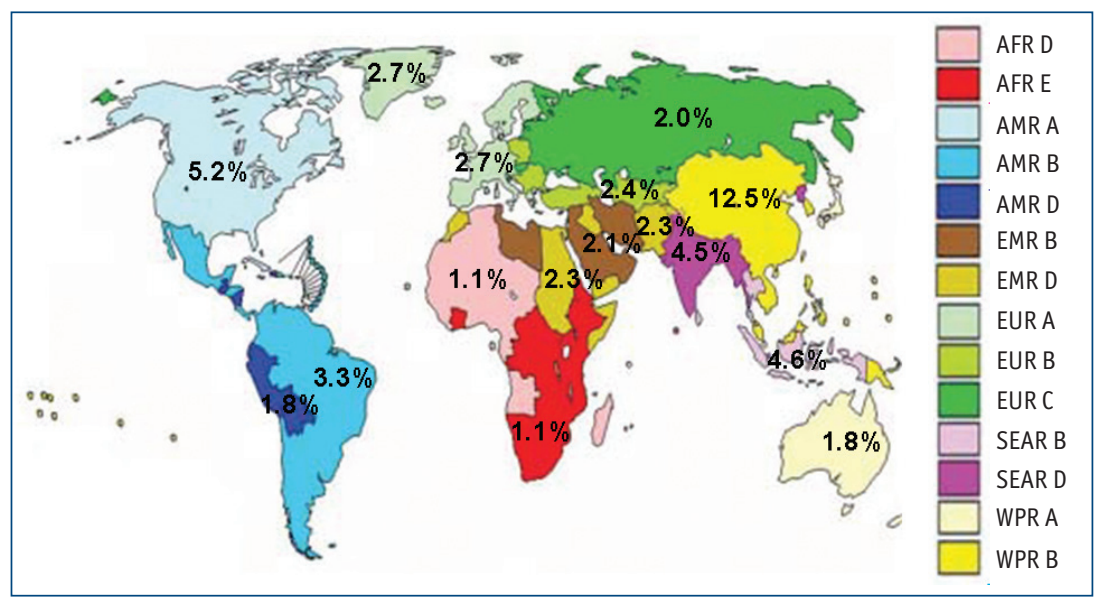

Figure 3

Estimated COPD DALYs by WHO regions, 2002. Figure modified from [10].

\section{Figures 2 and 3}

A: very low child and adult mortality; B: low child and adult mortality; D: high child and adult mortality; E: high child mortality and very high adult mortality; AFR: Africa; AMR: Americas; EMR: Easten Mediterranean; EUR: Europe; SEAR: South-East Asia; WPR: Western Pacific. 
In 2003, the European Respiratory Society (ERS) published the first edition of the European Lung White Book (the first comprehensive survey on respiratory health in Europe) [12], containing epidemiological and socio-economic data on respiratory diseases in Europe. Concerning mortality, the ERS report demonstrated that COPD deaths per year ranged from 200,000 to 300,000 , highlighting remarkable geographical differences. Overall, in European countries, the age-standardised death rate per 100,000 population of COPD ranged from 6 per 100,000 in Greece to 95 per 100,000 in Kyrgyzstan (figure 4). According to the WHO, COPD was the cause of death for $4.1 \%$ of males and $2.4 \%$ of females in Europe in 1997. In general, COPD mortality was 2-3 times higher in males than in females, showing an increasing trend in the elderly. However, COPD mortality increased among females in the northern European countries in the period of 1980-1990. For morbidity, studies from the last two decades have indicated that $4-6 \%$ of the adult European population suffer from clinically relevant COPD [12].

\section{Underdiagnosis of COPD}

COPD is a leading but under-recognised cause of morbidity and mortality worldwide. Indeed no other disease, responsible for such a high morbidity, mortality and cost burden, is so neglected by healthcare providers.

Information on obstructive lung disease (OLD) deaths is generally derived from the underlying cause of death on the death certificate (COPD or asthma, International Classification of Disease version 9 (ICD-9) codes 490-493, 496), but this information may underestimate the number of deaths to which OLD contributes. HANSELL et al. [13] compared the number of deaths in England and Wales (1993-1999) where OLD was the underlying cause of death or mentioned anywhere on the death certificate. The results showed that, if evaluating only the underlying cause of death, there was an underestimate of OLD of $40 \%$. Moreover, where OLD was not the underlying cause of death, the leading causes were circulatory system diseases, neoplasms and respiratory system diseases (excluding OLD) [13].

Holcuin et al. [14], from the US National Hospital Discharge Survey 1979-2001, showed that the yearly prevalence of hospital discharges with a diagnosis of COPD increased significantly, but mainly due to the proportion of hospital discharges with COPD listed as a secondary diagnosis $(\sim 12 \%)$, in comparison to discharges where COPD was the underlying cause of hospitalisation $(\sim 3 \%)$. Moreover, hospital discharges with primary or secondary COPD were also frequently diagnosed in association with other co-morbid conditions, such as cardiopulmonary diseases, pneumonia and lung cancer [14].

HUIART et al. [15] have previously shown that COPD patients present a nearly two-fold increase in CVD death rates when compared to the general population. Difficulty in determining the underlying cause of death among patients with multiple diseases, especially when the diseases share common risk factors, such as tobacco, has caused an overestimation of CVD as underlying cause of death and a consequent underestimation of COPD [15].

In a study on the change of the disease burden in China, HE et al. [7] showed that cancer (37.4\%) and heart disease (31.9\%) were the leading causes of death among Chinese adults,

\section{Figure 4}

Distribution of COPD mortality in Europe (2000). Figure reproduced with permission from [12]. (Source: OECD, www.oecd.org)

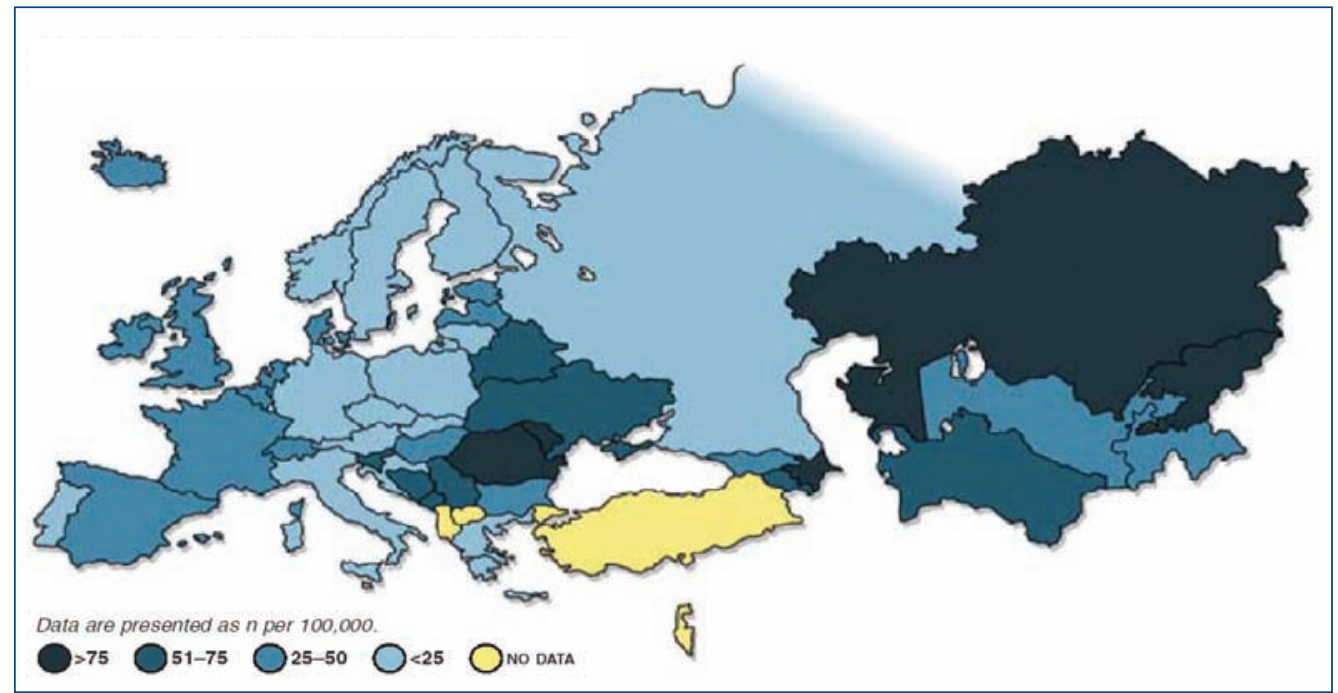


whereas the death rate for respiratory diseases was $9 \%$ [7]. The presidents of the major international respiratory societies, who participate in the Forum of International Respiratory Societies (FIRS), requested that $\mathrm{HE}$ et al. [7] reanalyse their data including "chronic pulmonary heart diseases" in the category "respiratory diseases" instead of the category "vascular diseases". In fact, the Presidents of the FIRS group believe that lung diseases could have at least the same importance as heart diseases, cancer and stroke, in terms of public health, if the death causes were properly re-classified. Indeed, when the category of "respiratory diseases" was re-classified to include COPD, asthma, lung cancer, pulmonary tuberculosis and "chronic pulmonary heart diseases", it became a leading cause of death in China, with a death rate of $19 \%$. This highlights the importance of a correct interpretation and presentation of health statistics, since governmental financial commitments largely depend on ranking of causes of death [16].

In their study from 2002, LINDSTRÖM et al. [17] assessed the under-diagnosis of COPD in two population samples of the same age, living in the same areas in northern Sweden. Two crosssectional studies on respiratory symptoms and diseases were carried out 6 years apart. Among the subjects diagnosed with airflow obstruction, only 26\% in 1986 and 31\% in 1992 had been diagnosed prior to the study as having chronic bronchitis, emphysema or COPD [17].

A review by HALBERT et al. [18] reported on 32 studies about COPD prevalence rates, representing 17 countries and eight WHO-classified regions. Prevalence estimates were based on spirometry (11 studies), respiratory symptoms (14 studies), patient-reported disease (10 studies) or WHO experts' opinion. The overall COPD prevalence rates ranged from $<1$ to $>18 \%$, and tended to vary with the method used to estimate the prevalence rate. Thus, some of the variations attributed to differences in risk exposure or population characteristics may be influenced by the methods and definitions used to measure disease [18].

Indeed, in the Po Delta Valley Study, VIEGI et al. [19] had already shown that in a general adult population sample the prevalence rates of airways obstruction ranged $11-57 \%$ (in subjects aged $>46$ years), applying different COPD definitions. They found a disparity based on a large prevalence of mild obstructive abnormalities when the old American Thoracic Society (ATS) criterion (forced expiratory volume in one second $(\mathrm{FEV} 1$ )/forced vital capacity (FVC) $<75 \%$ ) was

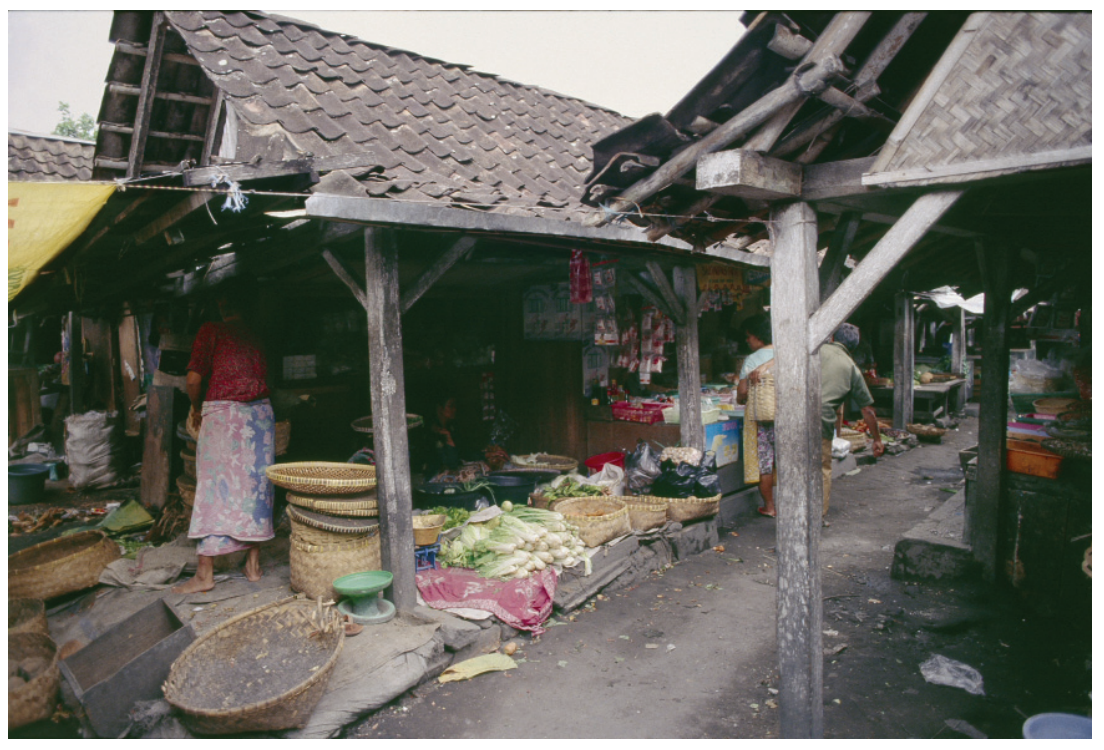

applied, as compared to a clinical criterion later adopted by the Global Initiative for Chronic Obstructive Lung Disease (GOLD) (FEV1/FVC $<70 \%$ ) and, especially, to the ERS criterion ( $\mathrm{FEV} 1 /$ vital capacity $(\mathrm{VC})<88 \%$ predicted in males and $<89 \%$ predicted in females) [19].

Celu et al. [20] have previously evaluated the impact of different definitions of airways obstruction on the estimated prevalence of obstruction in a population-based sample. On the basis of the Third National Health and Nutrition Examination Survey, obstructive airway disease was defined using the following criteria: 1) selfreported diagnosis of chronic bronchitis or emphysema; 2) $\mathrm{FEV} 1 / \mathrm{FVC}<0.70$ and $\mathrm{FEV} 1$ $<80 \%$ predicted (GOLD Stage IIA); 3) FEV1/FVC below the lower limit of normal; 4) FEV1/FVC $<88 \%$ predicted in males and $<89 \%$ predicted in females; 5) FEV1/FVC <0.70 ("fixed ratio", GOLD criterion Stage I+). The prevalence rate in adults ranged from $7.7 \%$ (self-reported) to 16.8\% (fixed ratio, GOLD criterion Stage I+), and for persons aged $>50$ yrs the fixed ratio criterion produced the highest rate estimates, ranging from $18.2 \%$ in subjects aged $50-54$ years to $41.7 \%$ in subjects aged $75-80$ years [20]. Thus, it seems that the GOLD criterion Stage I+ can overestimate the prevalence of COPD in older patients because it doesn't take into account the natural decline of FEV1/FVC with age.

HARDIE et al. [21] also criticised the applicability of the GOLD criterion to the whole population regardless of age. The extent of COPD misdiagnosis was examined using the GOLD definition in healthy, never-smoker, asymptomatic adults aged $>70$ years in Bergen, Norway. The results suggest that, using the GOLD criterion, $\sim 35 \%$ of healthy elderly subjects would be 
diagnosed as having at least mild COPD [21]. Indeed, the ATS/ERS Task Force on standardisation of lung function tests has endorsed another criterion for airflow obstruction definition, i.e. the lower limit of normal for per cent predicted FEV1/NC [22].

\section{Standardisation of COPD assessment} Since 2000, a number of initiatives have been taken to try to increase awareness about COPD: the guidelines on COPD by the WHO GOLD initiative [23] and the ATS/ERS [24]; the Burden of Obstructive Lung Disease (BOLD) initiative to facilitate standardised studies at an international level; and the proposal to set up large, longterm cohorts of patients to better define the natural history of COPD [9].

Better definitions of specific COPD phenotypes, better interventions and improved outcomes may permit a better understanding of the natural history of the disease. COPD has recently been described by the WHO GOLD initiative and by ATS/ERS guidelines as a disease that is "characterised by airflow limitation that is not fully reversible. The airflow limitation in most cases is both progressive and associated with an abnormal inflammatory response of the lungs to noxious particles or gases". Airflow limitation is the slowing of expiratory airflow as measured by spirometry, with a persistently low FEV 1 and a low FEV1/FVC ratio despite treatment. This progressive and relentless loss of lung function is the result of emphysema due to destruction of lung parenchyma and narrowing of small airways caused by chronic inflammation.

ChapMan et al. [9] described the aims of the BOLD initiative as follows: 1) to measure the prevalence of COPD and its risk factors in various countries around the world; 2) to estimate the

\section{Box 2. The BOLD model}

The BOLD project has the aim to develop a validated model to project the future burden of COPD. The BOLD model includes persons with COPD and those at risk for the development of the disease. Patients with COPD or those who develop COPD are categorised according to the GOLD staging criteria, and then divided into smokers and non-smokers. Capturing disease progression as it influences estimates of future costs is a key component of the model. The BOLD economic model estimates the costs related to the treatment of COPD and the types of healthcare resources consumed. The model estimates the current and future costs overall and per capita, stratified by severity. Moreover, the model reports the number of events in terms of hospitalisations, emergency department visits, outpatient visits, mortality and quality of life. The model is helpful for decision makers to estimate the current and future economic burden of COPD in their region. The model can be used to: determine which components of COPD have the most impact on overall costs; to estimate the resources that may be required in a 10-year period for treating COPD patients; and to evaluate the economic impact of various interventions (either real or hypothetical) [9]. burden of COPD in terms of its impact on quality of life, activity limitation, respiratory symptoms and use of healthcare services; and 3) to develop a validated model to project future burden of disease for COPD (box 2). The authors reported that, up to 2001 , only 32 prevalence surveys of COPD were published, specifically after the 1990s. Moreover, there was a broad variability of prevalence estimates across the studies attributed to different diagnostic and assessment methods in the surveys. Comparing age-specific death rates from lung cancer and COPD among males and females in the USA from 1997 to 2001, the results suggest that the death rates from both diseases increased markedly with age. However, the increase with age was continuous for COPD, whereas the lung cancer trend with age decreased in $>80$-year-old subjects.

Many authors have reported the lack of consensus in defining criteria for computing COPD prevalence in industrialised countries and the unavailability of prevalence figures in developing countries. To resolve these problems, LOPEZ et al. [10] created a model that back-calculates estimates of COPD incidence and prevalence. For calculating the prevalence, the relative risk of mortality from COPD was required. The authors then compared the current estimates, the 1990 estimates [8] and the range of published (up to 2002) estimates in the literature based on spirometry. In general, the current model estimates were more consistent with the results of the published literature. However, an underestimation of prevalence rates was confirmed when those computed through models were compared with those measured through spirometry in general population epidemiological studies.

\section{Comorbidity of asthma and COPD}

In Europe, direct and indirect costs of COPD and asthma were estimated at $\sim € 38.7$ and $€ 17.7$ billion in 2000, respectively, accounting for more than $50 \%$ of the costs for all respiratory diseases (€102 billion) (figure 5) [12].

Although asthma and COPD have usually been regarded as separated entities, with distinct clinical courses, recent studies have pointed out a relationship between these diseases. SIIVA et al. [25] showed that physician-diagnosed asthma is significantly associated with an increased risk for chronic bronchitis, emphysema and COPD at follow-up. VIEGI et al. [26] illustrated 


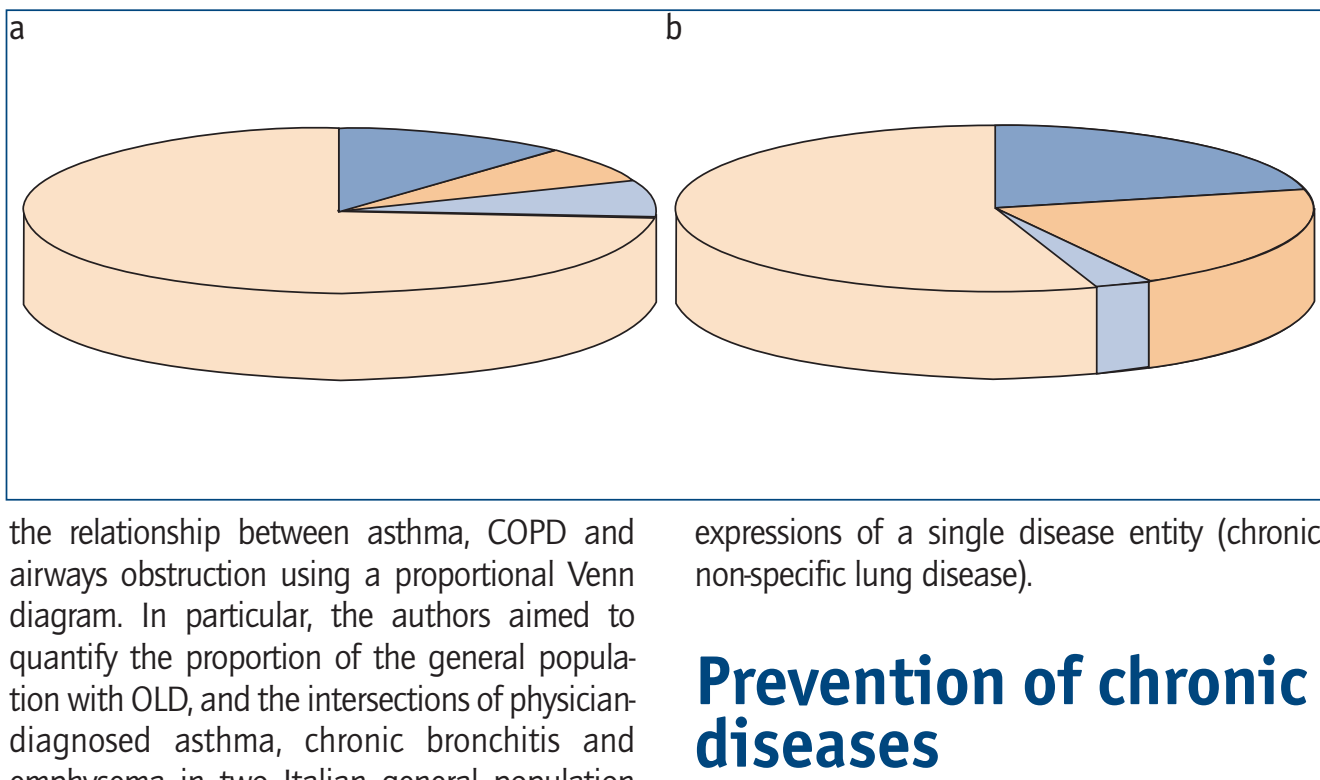
emphysema in two Italian general population samples, in relationship to airways obstruction determined through spirometry. About $18 \%$ of the Italian general population samples either reported the presence of OLD or showed spirometric signs of airways obstruction. Furthermore, asthma, chronic bronchitis and emphysema largely coexisted, predominantly in the elderly (6.7\% in males aged $\geq 64$ years).

Indeed, both endogenous and exogenous factors play a role in the pathogenesis of asthma and COPD, and both diseases involve genetic predisposition related to altered immune or atopic responses to irritants and pollutants, resulting in inflammation and bronchial hyperresponsiveness [27]. This notion has brought forward some reconsideration of the Dutch Hypothesis, advanced in the 1960s to sustain that various forms of airways obstruction, such as asthma and chronic obstructive bronchitis, which share airway inflammation and hyperresponsiveness, might be considered as different
EPPING-JORDAN et al. [28] presented a novel planning framework that can be used in these contexts: the stepwise framework for preventing chronic diseases. It was reported that "the framework offers a flexible and practical public health approach to assist ministries of health in balancing diverse needs and priorities while implementing evidence-based interventions such as those recommended by the WHO" (box 3). These include: promoting smoking cessation and controlling occupational exposures; encouraging healthcare systems to track patients' smoking and occupational histories, and to perform spirometry; developing early COPD identification programmes for all smokers and those with occupational risk. These recommendations can prevent COPD and respiratory diseases.

In this context, the ATS position paper on occupational burden of COPD and asthma estimated that population attributable risks due to work exposure are $~ 15 \%$ for chronic bronchitis

\section{Box 3. Stepwise framework for preventing chronic diseases}

The stepwise framework includes three main planning steps and three main implementation steps. The first planning step is to assess the current risk factor profile and burden of chronic diseases of a country or subpopulation. The key information required by countries is the distribution of risk factors among the population. The second planning step is to formulate and adopt a chronic disease policy based on prevention and control of the major chronic diseases; this policy should provide the basis for action in the next 5-10 years. Moreover, complementary policies should be developed at the state, province, district or municipal levels, depending on the configuration of each country's governance. The third planning step is to identify the policy implementation steps. These are the implementation steps: core, expanded and desirable. In deciding the package of interventions that constitute the first core implementation step (implementation in the short term), each country should consider the following factors: capacity for implementation, likely impact, acceptability and political support. The second implementation step is the expanded step: interventions that are feasible to implement with a realistically projected increase in, or reallocation of, resources in the medium term. The third and last implementation step is the desirable step: evidenced-based interventions that are beyond the reach of existing resources [28].

Figure 5

Distribution of costs (excluding mortality and rehabilitation costs) for a) COPD (total cost €38.7 billion) and b) asthma (total cost $€ 17.7$ billion) in Europe (2000). Figure reproduced with permission from [12]. 


\section{Educational questions}

1. What are the principal risk factors for chronic diseases?

2. Why is it so important to know the burden of COPD?

3. Chronic diseases are a major contributor to death and DALYs in which low-income country?

4. What are the recommendations for reducing the prevalence of COPD? and for asthma, and 19\% for lung function impairment [29]. Moreover, DRISColl et al. [30] reported that, in 2000, there were 318,000 deaths worldwide from COPD due to occupational airborne exposure.

FrIEDMAN et al. [31] described the effects of traffic changes in Atlanta (GA, USA), during the 1996 Summer Olympic Games on childhood asthma events (sample of children aged 1-16 years living in the five central counties of metropolitan Atlanta). They compared the 17 days of the Olympic Games (July 19-August 4, 1996) to a baseline period consisting of the 4 weeks before and 4 weeks after the Olympic Games. The results of the study showed an association between the prolonged reduction in ozone pollution and lower rates of childhood asthma events.

Clancy et al. [32] assessed the effect of the ban on coal sales on particulate air pollution and death rates in Dublin. This study is very important because there is little direct evidence that diminished particulate air pollution concentrations would lead to reductions in death rates. Concentrations of air pollution and directly standardised non-trauma, respiratory and cardiovascular death rates were compared for 72 months before and after the ban of coal sales. In Dublin, average black smoke concentrations declined by $35.6 \mu \mathrm{g}$ per $\mathrm{m}^{3}$ (70\%) after the intervention. Adjusted non-trauma death rates decreased by $5.7 \%$ (95\% confidence interval (Cl) $4-7 \%$ ), respiratory deaths by $15.5 \%$ (95\% Cl 12-19\%) and cardiovascular deaths by $10.3 \%$ (95\% Cl 8-13\%). Therefore, it was shown that control of particulate air pollution can substantially diminish human respiratory and cardiovascular death rates.

KUNZL [33] has recently estimated the health benefit that is possible to obtain through an abatement scenario of the main risk factors for respiratory diseases and, in particular, of smoking, environmental tobacco smoke (ETS) and outdoor air pollution. It was estimated that $>70 \%$ of chronic bronchitis cases could be prevented if the prevalence rates of active smoking, ETS and particulate matter with aerodynamic diameter $<10$ $\mu \mathrm{m}(\mathrm{PM} 10)$ annual means were reduced to $5 \%$, $2.5 \%$ and $5 \mu \mathrm{g}$ per $\mathrm{m}^{3}$, respectively.

These data provide support for efforts to reduce the air pollution caused by vehicular traffic or combustion sources in order to improve human health.

\section{Conclusion}

It is essential that the Millennium Development Goals are expanded to include the reduction of chronic disease, comprising respiratory illness. Indeed, by reducing deaths from chronic diseases by $2 \%$ annually, 36 million deaths could be prevented by 2015 .

Moreover, chronic diseases are not only a problem for rich nations. In 2005, 80\% of deaths occurred in low-income and middleincome countries, in particular among the countries that do not have resources to easily pursue healthy choices.

With this review, we hope to have underlined the importance of considering chronic diseases in the mainstream of global action on health and the need for all sectors of our society to contribute to reducing health risk factors and promoting better quality of life. Indeed, a multisectoral policy approach is essential to reverse the negative trends in the global incidence of chronic disease [34]. 


\section{References}

1. Horton $R$. The neglected epidemic of chronic disease. Lancet 2005; 366: 1514.

2. Strong K, Mathers C, Leeder S, Beaglehole R. Preventing chronic diseases: how many lives can we save? Lancet 2005; $306:$ 1578-1582.

3. World Health Organization. World Global Report 2005. Preventing chronic diseases: a vital investment. Geneva, World Health Organization (WHO), 2005.

4. Murray CJL, Lopez AD. Global Health Statistics. Global Burden of Disease and Injury Series. Boston, Harvard School of Public Health, 1996.

5. Reddy KS, Shah B, Varghese C, Ramadoss A. Responding to the threat of chronic diseases in India. Lancet 2005; 366 : 1746-1751.

6. Wang L, Kong L, Wu F, Bai Y, Burton R. Preventing chronic diseases in China. Lancet 2005; 366: 1821-1824.

7. He J, Gu D, Wu X et al. Major causes of death among men and women in China. N Engl J Med 2005; 353: 1124-1134.

8. Murray CJL, Lopez AD. Alternative projections of mortality and disability by cause 1990-2020. Lancet 1997; 349: 1498-1504.

9. Chapman KR, Mannino DM, Soriano JB, et al. Epidemiology and costs of chronic obstructive pulmonary disease. Eur Respir J 2006; $27:$ 188-207.

10. Lopez $A D$, Shibuya $K$, Rao $C$, et al. Chronic obstructive pulmonary disease: current burden and future projections. Eur Respir J 2006; 27: 397-412.

11. Menezes AMB, Perez-Padilla R, Jardim JRB, et al. Chronic obstructive pulmonary disease in five Latin American cities (the PLATINO study): a prevalence study. Lancet 2005; 366: 1875-1881.

12. European Respiratory Society. Chronic Obstructive Pulmonary Disease. In: European Lung White Book-the first comprehensive survey on respiratory health in Europe. Loddenkemper R, Gibson GJ, Sibille Y, eds. Sheffield, ERSJ, 2003.

13. Hansell AL, Walk JA, Soriano JB. What do chronic obstructive pulmonary disease patients die from? A multiple cause coding analysis. Eur Respir J 2003; 22: 809-814.

14. Holguin F, Folch E, Redd SC, Mannino DM. Comorbidity and mortality in COPD-related hospitalizations in the United States, 1979 to 2001. Chest 2005; 128: 2005-2011.

15. Huiart L, Ernst P, Suissa S. Cardiovascular morbidity and mortality in COPD. Chest 2005; 128: 2640-2646.

16. Wagner PD, Viegi G, Luna CM, Fukuchi Y, Kvale PA, Sony AEL. Major causes of death in China. N Engl J Med 2006; $354: 874$.

17. Lindström $M$, Jonsson $E$, Larsson $K$, Lundback $B$. Underdiagnosis of chronic obstructive pulmonary disease in Northern Sweden. Int J Tuberc Lung Dis 2002; 6: 76-84.

18. Halbert RJ, Isonaka S, Georg D, Iqbal A. Interpreting COPD prevalence estimates. What is the true burden of disease? Chest 2003; 123: 1684-1692.

19. Viegi G, Pedreschi M, Pistelli F, et al. Prevalence of airways obstruction in a general population: European Respiratory Society vs American Thoracic Society Definition. Chest 2000; 117: 339S-345S.

20. Celli BR, Halbert RJ, Isonaka S, Schau B. Population impact of different definitions of airway obstruction. Eur Respir J 2003; 22: 268-273.

21. Hardie JA, Buist AS, Vollmer WM, Ellingsen I, Bakke PS, Mùrkve O. Risk of over-diagnosis of COPD in asymptomatic elderly never-smokers. Eur Respir J 2002; 20: 1117-1122.

22. Pellegrino R, Viegi G, Brusasco RO, et al. Interpretative strategies for lung function tests. Eur Respir J 2005; $26: 948-968$.

23. Pauwels RA, Buist AS, Calverley PM, Jenkins CR, Hurd SS, GOLD Scientific Committee. Global strategy for the diagnosis, management, and prevention of chronic obstructive pulmonary disease. NHLBI/WHO Global Initiative for Chronic Obstructive Lung Disease (GOLD) Workshop summary. Am J Respir Crit Care Med 2001; 163: 1256-1276.

24. Celli BR, MacNee W, and Commitee members. Standard for the diagnosis and treatment of patients with COPD: a summary of the ATS/ERS position paper. Eur Respir J 2004; 23: 932-946.

25. Silva GE, Sherrill DL, Guerra S, Barbee RA. Asthma as a risk factor for COPD in a longitudinal study. Chest 2004; 126: 59-65.

26. Viegi $G$, Matteelli $G$, Angino A, et al. The proportional Venn diagram of obstructive lung disease in the Italian general population. Chest 2004; 126: 1093-1101.

27. Bleecker ER. Similarities and differences in asthma and COPD. The Dutch Hypothesis. Chest 2004; 126: 93s-95s.

28. Epping-Jordan JE, Galea G, Tukuitonga C, Beaglehole R. Preventing chronic diseases: taking stepwise action. Lancet 2005; 366: 1667-1671.

29. Balmes J, Becklake M, Blanc P, et al. American Thoracic Society Statement. Occupational contribution to the burden of the airway disease. Am J Respir Crit Care Med 2003; 167: 787-797.

30. Driscoll T, Nelson DI, Steenland K, et al. The global burden of non-malignant respiratory disease due to occupational airborne exposure. Am J Ind Med 2005; 48: 432-445.

31. Friedman MS, Powell KE, Hutwagner L, Graham LM, Teague WG. Impact of changes in transportation and commuting behaviours during the 1996 Summer Olympic Games in Atlanta on air quality and childhood asthma. JAMA 2001; 285: 897-905.

32. Clancy L, Goodman P, Sinclair H, Dockery DW. Effect of air-pollution control on death rates in Dublin, Ireland: an intervention study. Lancet 2002; 360: 1210-1214.

33. Künzli N. The public health relevance of air pollution abatement. Eur Respir J 2002; 20: 198-209.

34. Yach D, Hawkes C, Gould CL, Hofman KJ. The global burden of chronic diseases. Overcoming impediments to prevention and control. JAMA 2004; 291: 2616-2622.

\section{Suggested answers}

1. Age, smoke and air pollution.

2. Because COPD will become the third cause of mortality by 2020 worldwide.

3. China: chronic diseases contribute to $80 \%$ of deaths and $70 \%$ of DALYs.

4. Promotion of smoking cessation and control of occupational exposures; encouragement for healthcare systems to track their patients' smoking and occupational histories and to perform spirometry; development of a programme for the abatement of indoor and outdoor air pollution; development of a programme for improved nutrition. 